\title{
Free-radical scavenging capacity and reducing power of wild edible mushrooms from northeast Portugal: Individual cap and stipe activity
}

\author{
Isabel C.F.R. Ferreira *, Paula Baptista, Miguel Vilas-Boas, Lillian Barros \\ CIMO-Escola Superior Agrária, Instituto Politécnico de Bragança, Campus de Santa Apolónia, Apartado 1172, 5301-855 Bragança, Portugal
}

Received 2 May 2005; accepted 30 November 2005

\begin{abstract}
The antioxidant properties of two wild edible mushroom species from the northeast of Portugal, Lactarius deliciosus (L.) Gray and Tricholoma portentosum (Fr.) Quél., were evaluated. Methanolic extracts from the entire mushroom, the cap and the stipe, separately, were screened for their reducing power and free radical scavenging capacity by chemical assays. The total phenolic content was determined, in order to assess its effect on the extract's antioxidant activity. Both two species showed antioxidant potential; but $L$. deliciosus proved to be more active. The portion of the mushroom used had an influence on the results obtained, with the cap methanolic extracts exhibiting the greatest antioxidant effect.
\end{abstract}

(c) 2005 Elsevier Ltd. All rights reserved.

Keywords: Wild edible mushrooms; Lactarius deliciosus; Tricholoma portentosum; Scavenging effect; Reducing power; Total phenols

\section{Introduction}

Reactive oxygen species are formed during normal cellular metabolism, but when present in high concentration they become toxic. Mammalian cells possess intracellular defences such as superoxide dismutase, catalase or glutathione peroxidase, in order to protect the cells against excessive levels of free radicals. Also exogenous addition of compounds such as vitamins (A, E, $\beta$-carotene), minerals (selenium, zinc), or proteins (transferrin, ceruloplasmin, albumin) can provide additional protection (Ostrovidov et al., 2000). These natural antioxidants or other compounds that can neutralize free radicals may be of central importance in the prevention of vascular diseases, some forms of cancer (Halliwell, 1997; Nakayama, Yamada, Osawa, \& Kawakishi, 1993) and oxidative stress responsible for DNA, protein and membrane damage. Superoxide, hydrogen peroxide and hydroxyl radicals, which are mutagens produced by radiation, are also by-products of normal metabolism. Lipid peroxidation is also a major cause of food

\footnotetext{
${ }^{*}$ Corresponding author. Tel.: +351273 303219; fax: +351273325405. E-mail address: iferreira@ipb.pt (I.C.F.R. Ferreira).
}

deterioration, affecting colour, flavour, texture and nutritional value (Halliwell \& Gutteridge, 1999). Even though it is unclear whether active compounds are active against free radicals after being absorbed and metabolized by cells in the body, radical-scavenging assays have gained acceptance for their capacity to rapidly screen materials of interest.

The search for new products with antioxidative properties is a very active domain of research. Mushrooms have been used as food and food-flavouring material in soups and sauces for centuries, due to their unique and subtle flavour. Recently, they have become attractive as functional foods and as a source of physiologically beneficial medicines, while being devoid of undesirable side-effects (Sagakami, Aohi, Simpson, \& Tanuma, 1991). Mushrooms were also found to be medically active in several therapies, such as antitumour, antibacterial, antiviral, haematological and immunomodulating treatments. In particular, mushrooms useful against cancers of the stomach, esophagus, lungs, etc., are known in China, Japan, Korea, Russia, the United States and Canada. Both cellular components and secondary metabolites of a large number of mushrooms have been shown to affect the immune system of the host and therefore could be used to treat a variety of diseases (Wasser 
$\&$ Weis, 1999). The antioxidative and free radical scavenging properties of the phenolic content of mushroom methanolic extracts have been reported, suggesting possible protective roles of these compounds, due to their ability to capture metals, inhibit lipoxygenase and scavenge free radicals (Mau, Chang, Huang, \& Chen, 2004). Recently, Valentão et al. (2005a) identified the presence of six phenolic compounds (3-, 4- and 5-O-caffeoylquinic acid, caffeic acid, $p$-coumaric acid and rutin) and five organic acids (citric, ascorbic, malic, shikimic and fumaric acids) in wild edible mushroom Cantharellus cibarius Fr., kept under four different conditions (dried, frozen, preserved in olive oil and in vinegar). The organic acids citric, ketoglutaric, malic, succinic, oxalic, ascorbic, quinic, shikimic and fumaric were also found in the edible mushrooms Amanita caesarea (Scop.) Pers., Boletus edulis Bull., Gyroporus castaneus (Bull.) Quél., Lactarius deliciosus (L.) Gray, Suillus collinitus (Fr.) Kuntze and Xerocomus chrysenteron (Bull.) Quél. (Valentão et al., 2005b).

The northeast of Portugal, due to its climatic conditions and flora diversity, is one of the European regions with a high diversity of wild edible mushrooms, some of them with great gastronomic relevance. Within the local edible species, L. deliciosus (L.) Gray, B. edulis Bull., Hydnum rufescens Pers. and Cantharellus cibarius Fr. are the most important because of their high consumption by the rural population and their economic value in the markets, of France and Spain (Baptista, Branco, \& Martins, 2003; Martins, Baptista, Sousa, Meireles, \& Pais, 2002).

Herein, we report chemical assays on the antioxidant activity of two wild edible mushroom species, $L$. deliciosus (L.) Gray and Tricholoma portentosum (Fr.) Quél., from northeast Portugal. For the first time, the entire mushroom, the cap and the stipe individually were studied in order to compare their antioxidant properties.

\section{Materials and methods}

\subsection{Standards and reagents}

Standards BHA (2-tert-butyl-4-methoxyphenol), $\alpha$ tocopherol and gallic acid were purchased from Sigma (St. Louis, MO, USA). 2,2-Diphenyl-1-picrylhydrazyl (DPPH) was obtained from Alfa Aesar (Ward Hill, MA, USA). All other chemicals were obtained from Sigma Chemical Co. (St. Louis, MO, USA). Methanol was obtained from Pronalab (Lisbon, Portugal). Water was treated in a Milli-Q water purification system (TGI Pure Water Systems, USA).

\subsection{Samples}

Samples of $L$. deliciosus and $T$. portentosum were collected under live pine trees (Pinus sp.), in Bragança (northeast of Portugal), in autumn 2004. After collection, the mushrooms were grouped by taxon and were air-dried in a liophylizator (Ly-8-FM-ULE, Snijders, Holland) before analysis. Taxonomic identification was made according to several authors (Bon, 1988; Courtecuisse, 1999; Courtecuisse \& Duhem, 1995; Marchand, 1971-1986; Moser, 1983) and representative voucher specimens were deposited at the herbarium of Escola Superior Agrária of Instituto Politécnico de Bragança.

\subsection{Sample preparation}

All the assays were performed using either the entire mushroom, the cap or the stipe separately.

A fine dried mushroom powder (20 mesh) sample (10 g) was extracted by stirring with $100 \mathrm{ml}$ of methanol at $25^{\circ} \mathrm{C}$ at $150 \mathrm{rpm}$ for $24 \mathrm{~h}$ and filtered through Whatman No. 4 paper. The residue was then extracted with two additional $100 \mathrm{ml}$ portions of methanol, as described earlier. The combined methanolic extracts were evaporated at $40{ }^{\circ} \mathrm{C}$ to dryness and redissolved in methanol at a concentration of $50 \mathrm{mg} / \mathrm{ml}$, and stored at $4{ }^{\circ} \mathrm{C}$ until further use.

\subsection{Determination of total phenolic content}

Phenolic compounds concentration in the mushroom methanolic extracts was estimated by a colorimetric assay, based on procedures described by Singleton and Rossi with some modifications (Singleton \& Rossi, 1965). Briefly, $1 \mathrm{ml}$ of sample was mixed with $1 \mathrm{ml}$ of Folin and Ciocalteu's phenol reagent. After $3 \mathrm{~min}, 1 \mathrm{ml}$ of saturated sodium carbonate solution was added to the mixture and adjusted to $10 \mathrm{ml}$ with distilled water. The reaction was kept in the dark for 90 min, after which the absorbance was read at $725 \mathrm{~nm}$ (Analytikijena 200-2004 spectrophotometer). Gallic acid was used to calculate the standard curve $(0.01-$ $0.4 \mathrm{mM}$ ). Estimation of the phenolic compounds was carried out in triplicate. The results were mean values \pm standard deviations and expressed as $\mathrm{mg}$ of gallic acid equivalents/g of extract (GAEs).

\subsection{Reducing power assay}

The reducing power was determined according to the method of Oyaizu (1986). Various concentrations of mushroom methanolic extracts $(2.5 \mathrm{ml})$ were mixed with $2.5 \mathrm{ml}$ of $200 \mathrm{mmol} / \mathrm{l}$ sodium phosphate buffer $(\mathrm{pH}$ 6.6) and $2.5 \mathrm{ml}$ of $1 \%$ potassium ferricyanide. The mixture was incubated at $50{ }^{\circ} \mathrm{C}$ for $20 \mathrm{~min}$. After $2.5 \mathrm{ml}$ of $10 \%$ trichloroacetic acid (w/v) were added, the mixture was centrifuged at $650 \mathrm{rpm}$ for $10 \mathrm{~min}$. The upper layer $(5 \mathrm{ml})$ was mixed with $5 \mathrm{ml}$ deionised water and $1 \mathrm{ml}$ of $0.1 \%$ of ferric chloride, and the absorbance was measured at $700 \mathrm{~nm}$ : higher absorbance indicates higher reducing power. The assays were carried out in triplicate and the results are expressed as mean values \pm standard deviations. The extract concentration providing 0.5 of absorbance $\left(\mathrm{EC}_{50}\right)$ was calculated from the graph of absorbance at $700 \mathrm{~nm}$ against extract concentration. BHA and $\alpha$-tocopherol were used as standards. 


\subsection{Radical-scavenging activity (RSA) assay}

The capacity to scavenge the "stable" free radical 2,2diphenyl-1-picrylhydrazyl (DPPH) was monitored according to the method of Hatano, Kagawa, Yasuhara, and Okuda (1988). Various concentrations of methanolic extracts from mushrooms $(0.3 \mathrm{ml})$ were mixed with $2.7 \mathrm{ml}$ of methanolic solution containing DPPH radicals $\left(6 \times 10^{-5} \mathrm{~mol} / \mathrm{l}\right)$. The mixture was shaken vigorously and left to stand for $60 \mathrm{~min}$ in the dark (until stable absorption values were obtained). The reduction of the DPPH radical was measured by monitoring continuously the decrease of absorption at $517 \mathrm{~nm}$. The radical-scavenging activity (RSA) was calculated as a percentage of DPPH discolouration using the equation: $\% \mathrm{RSA}=100 \times\left(1-A_{\mathrm{c}} / A_{\mathrm{D}}\right)$, where $A_{\mathrm{c}}$ is the absorbance of the solution when the extract has been added at a particular level, and $A_{\mathrm{D}}$ is the absorbance of the DPPH solution. The assays were carried out in triplicate and the results are expressed as mean values \pm standard deviations. The extract concentration providing $50 \%$ inhibition $\left(\mathrm{EC}_{50}\right)$ was calculated from the graph of RSA percentage against extract concentration. BHA and $\alpha$-tocopherol were used as standards.

\section{Results and discussion}

Two wild edible mushroom species ( $L$. deliciosus, T. portentosum) from the northeast of Portugal were evaluated for their content in total phenols, reducing power and free-radical scavenging capacity. Total phenolic content was determined using Folin and Ciocalteu's phenol reagent. The reducing power was evaluated measuring absorbance at $700 \mathrm{~nm}$ after mixing the samples with ferric compounds; higher absorbance indicates higher reducing power. The scavenging effects on DPPH radicals were determined measuring the decay in absorbance at $517 \mathrm{~nm}$ due to the DPPH radical reduction, indicating the antioxidant activity of the compounds in a short time (Amarowicz, Pegg, Rahimi-Moghaddam, Barl, \& Weil, 2004; Cheung, Cheung, \& Ooi, 2003; Mau, Lin, \& Song, 2002; Yen \& Hung, 2000). All the assays were carried out using the entire mushroom, the cap and the stipe separately.

\subsection{Determination of total phenols}

It had been reported that the antioxidant activity of plant materials is well correlated with the content of their phenolic compounds (Velioglu, Mazza, Gao, \& Oomah, 1998). In fact, phenols such as BHT (butylated hydroxytol- uene) and gallate, are known to be effective antioxidants. Table 1 shows the phenols concentration in the mushroom extracts, expressed as mg of gallic acid equivalents (GAEs) per $g$ of extract.

The contents of total phenols in methanolic extracts from $L$. deliciosus were $17.25 \pm 0.65 \mathrm{mg} / \mathrm{g}$ while in $T$. portentosum extracts contained only $10.80 \pm 0.47 \mathrm{mg} / \mathrm{g}$. The portion of the mushroom used influenced the results obtained. As expected, the extracts from the entire mushroom showed higher phenolic content than either the cap or the stipe. The amount of phenolic compounds in the cap methanolic extracts $(10.66 \pm 0.52 \mathrm{mg} / \mathrm{g}$ for $L$. deliciosus and $6,57 \pm 0.31 \mathrm{mg} / \mathrm{g}$ for $T$. portentosum) was higher than the amount found in stipe extracts $(6.31 \pm 0.29 \mathrm{mg} / \mathrm{g}$ for $L$. deliciosus and $3,91 \pm 0.17 \mathrm{mg} / \mathrm{g}$ for $T$. portentosum).

The higher content of total phenols in the L. deliciosus extracts might account for the better results found in their reducing power and radical scavenging effect on DPPH radicals.

\subsection{Reducing power assay}

Figs. 1 and 2 show the reducing power of mushrooms methanolic extracts as a function of their concentration. In this assay, the yellow colour of the test solution changes to various shades of green and blue, depending on the reducing power of each compound. The presence of reducers (i.e. antioxidants) causes the reduction of the $\mathrm{Fe}^{3+} /$ ferricyanide complex to the ferrous form. Therefore, measuring the formation of Perl's Prussian blue at $700 \mathrm{~nm}$ can monitor the $\mathrm{Fe}^{2+}$ concentration.

The reducing power of the mushroom methanolic extracts increased with concentration. The reducing power

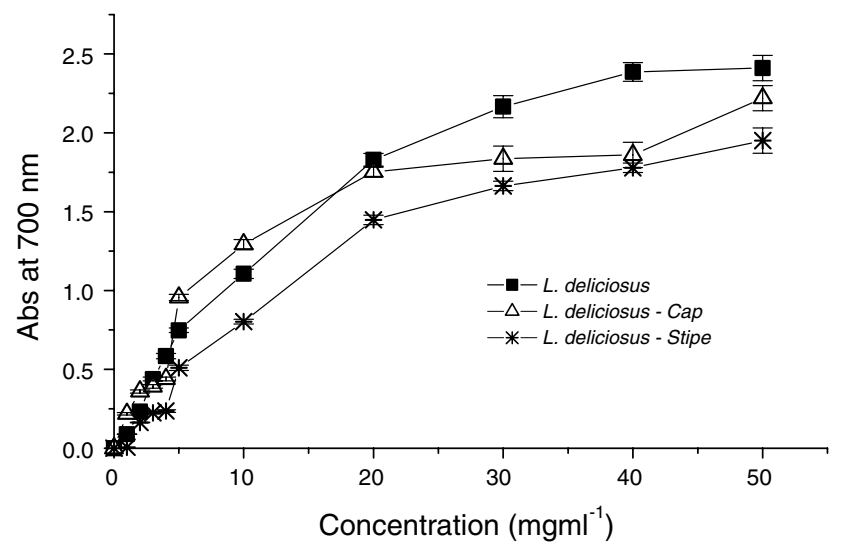

Fig. 1. Reducing power of methanolic extracts from L. deliciosus. Each value is expressed as mean \pm standard deviation $(n=3)$.

Table 1

Contents of total phenols in methanolic extracts from two wild edible mushrooms

\begin{tabular}{llllll}
\hline Content $^{\mathrm{a}}(\mathrm{mg} / \mathrm{g})$ & \multicolumn{1}{l}{} \\
\hline Lactarius deliciosus & L. deliciosus $(\mathrm{cap})$ & L. deliciosus $($ stipe) & Tricholoma portentosum & T. portentosum (cap) & T. portentosum (stipe) \\
\hline $17.25 \pm 0.65$ & $10.66 \pm 0.52$ & $6.31 \pm 0.29$ & $10.80 \pm 0.47$ & $6.57 \pm 0.31$ & $3.91 \pm 0.17$ \\
\hline
\end{tabular}

${ }^{\mathrm{a}}$ Each value is expressed as mean \pm standard deviation $(n=3)$. 


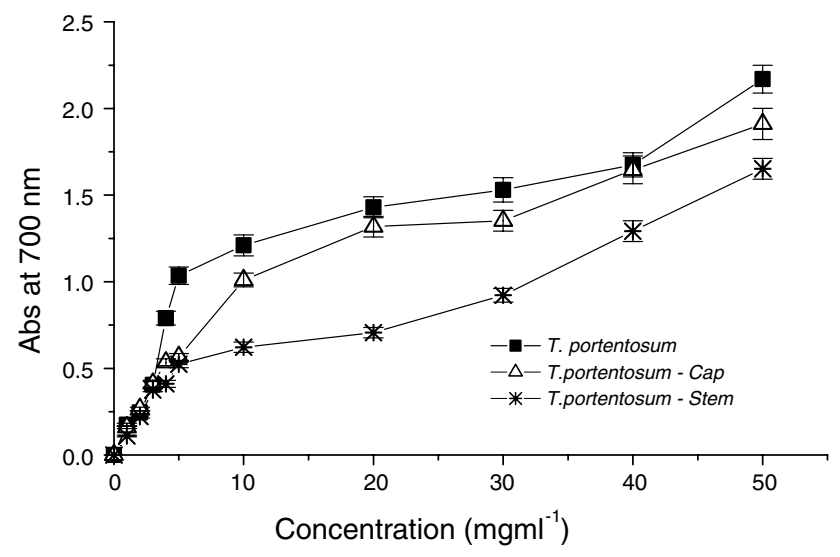

Fig. 2. Reducing power of methanolic extracts from $T$. portentosum. Each value is expressed as mean \pm standard deviation $(n=3)$.

of both species was excellent (Figs. 1 and 2); at $50 \mathrm{mg} / \mathrm{ml}$ the reducing power was higher than 1.65 and in the order L. deliciosus $>L$. deliciosus cap $>T$. portentosum $>$ L. deliciosus stipe $>T$. portentosum cap $>>T$. portentosum stipe. At $5 \mathrm{mg} / \mathrm{ml}$, the reducing powers of the methanolic extracts from wild edible mushrooms were $0.52-0.96$, and at $1 \mathrm{mg} /$ $\mathrm{ml}$ were $0.006-0.22$. Reducing power of BHA at $3.6 \mathrm{mg} / \mathrm{ml}$ and $\alpha$-tocopherol at $8.6 \mathrm{mg} / \mathrm{ml}$ was only 0.12 and 0.13 , respectively. Methanolic extracts from $T$. portentosum showed slightly lower reducing power values (Fig. 2) than L. deliciosus (Fig. 1). The extracts obtained from the mushroom cap proved to be a better source of antioxidants than extracts from the mushroom stipe. The use of the entire mushroom increased the reducing power (at $50 \mathrm{mg} / \mathrm{ml}-$ 2.41 for $L$. deliciosus and 2.17 for $T$. portentosum).

It was reported that the reducing power of mushrooms might be due to their hydrogen-donating ability (Shimada, Fujikawa, Yahara, \& Nakamura, 1992). Accordingly, L. deliciosus might contain higher amounts of reductone, which could react with free radicals to stabilise and block radical chain reactions.

\subsection{Radical-scavenging activity ( $R S A$ ) assay}

The RSA of mushrooms extracts was tested using a methanolic solution of the "stable" free radical, DPPH. Unlike laboratory-generated free radicals such as the hydroxyl radical and superoxide anion, DPPH has the advantage of being unaffected by certain side reactions, such as metal ion chelation and enzyme inhibition (Amarowicz et al., 2004). A freshly prepared DPPH solution exhibits a deep purple colour with absorption maximum at $517 \mathrm{~nm}$. This purple colour generally fades/disappears when an antioxidant is present in the medium. Thus, antioxidant molecules can quench DPPH free radicals (i.e., by providing hydrogen atoms or by electron donation, conceivably via a free-radical attack on the DPPH molecule) and convert them to a colourless/bleached product (i.e., 2,2-diphenyl-1-hydrazine, or a substituted analogous hydrazine), resulting in a decrease in absorbance at
$517 \mathrm{~nm}$. Hence, the more rapidly the absorbance decreases, the more potent the antioxidant activity of the extract. Free radical scavenging is one of the known mechanisms by which antioxidants inhibit lipid oxidation. This test is a commonly employed assay in antioxidant studies of specific compounds or extracts across a short time scale.

The RSA values of methanolic extracts from $L$. deliciosus and $T$. portentosum were examined and compared against one another (Figs. 3 and 4). Results are expressed as the ratio percentage of sample absorbance decrease and the absorbance of DPPH solution in the absence of extract at $517 \mathrm{~nm}$.

From the analysis of Figs. 3 and 4, we can conclude that the scavenging effects of mushrooms methanolic extracts on DPPH radicals increased with the concentration increase and were high $(79.1-84.3 \%$ at $50 \mathrm{mg} / \mathrm{ml})$ for $L$. deliciosus. Methanolic extracts from $T$. portentosum presented moderate RSA values $(30.4-65.0 \%$ at $50 \mathrm{mg} / \mathrm{ml})$ and lower than the other species. However, the scavenging effects of BHA $(3.6 \mathrm{mg} / \mathrm{ml})$ and $\alpha$-tocopherol $(8.6 \mathrm{mg} / \mathrm{ml})$ were $96 \%$ and $95 \%$, respectively. The extracts obtained from the mushroom cap scavenged DPPH radicals by higher per-

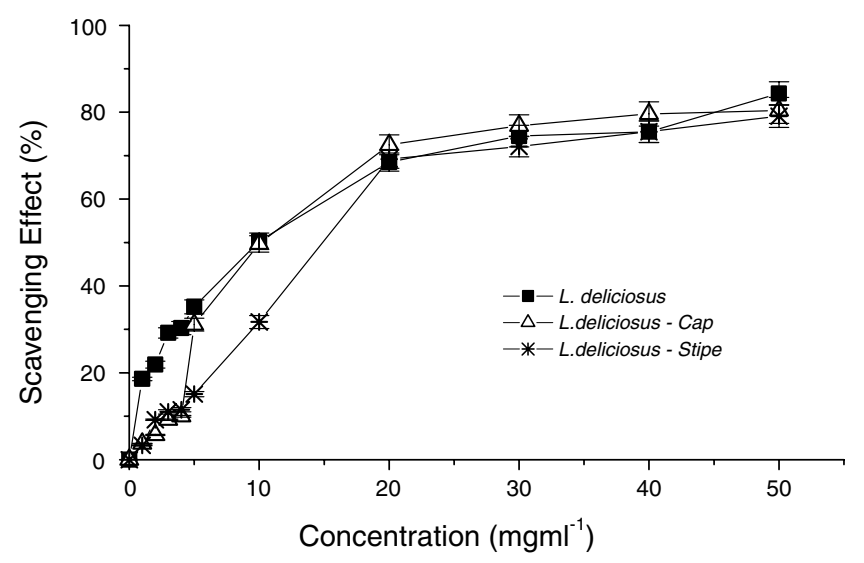

Fig. 3. Scavenging activity (\%) on DPPH radicals of methanolic extracts from $L$. deliciosus. Each value is expressed as mean \pm standard deviation $(n=3)$.

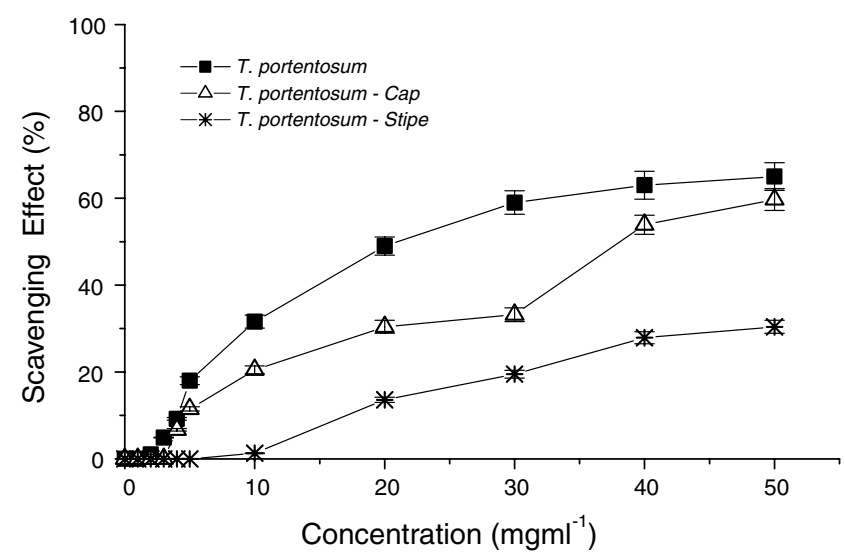

Fig. 4. Scavenging activity (\%) on DPPH radicals of methanolic extracts from $T$. portentosum. Each value is expressed as mean \pm standard deviation $(n=3)$. 
Table 2

$\mathrm{EC}_{50}$ values $^{\mathrm{a}, \mathrm{b}}(\mathrm{mg} / \mathrm{ml})$ of mushrooms extracts in reducing power and DPPH scavenging assays

\begin{tabular}{lll}
\hline Samples & Reducing power $\left(\mathrm{EC}_{50}{ }^{\mathrm{a}}\right)$ & $\mathrm{DPPH}\left(\mathrm{EC}_{50}{ }^{\mathrm{b}}\right)$ \\
\hline Lactarius deliciosus & 3.42 & 8.52 \\
L. deliciosus (cap) & 3.58 & 11.9 \\
L. deliciosus (stipe) & 6.69 & 15.1 \\
Tricholoma portentosum & 3.12 & 22.9 \\
T. portentosum (cap) & 3.69 & 40.2 \\
T. portentosum (stipe) & 4.82 & $>50$
\end{tabular}

${ }^{\text {a }} \mathrm{EC}_{50}(\mathrm{mg} / \mathrm{ml})$ : effective concentration at which the absorbance is 0.5 .

${ }^{b} \mathrm{EC}_{50}(\mathrm{mg} / \mathrm{ml})$ : effective concentration at which $50 \%$ of DPPH radicals are scavenged.

centages ( $80.4 \%$ for L. deliciosus and $59.7 \%$ for T. portentosum at $50 \mathrm{mg} / \mathrm{ml}$ ) than extracts from the stipe mushroom (79.1\% for L. deliciosus and $30.4 \%$ for $T$. portentosum at $50 \mathrm{mg} / \mathrm{ml}$ ). The use of the entire mushroom increased the RSA values (at $50 \mathrm{mg} / \mathrm{ml}-80.4 \%$ for $L$. deliciosus and $65.0 \%$ for $T$. portentosum).

In Table 2, we present the $\mathrm{EC}_{50}$ values for reducing power and DPPH scavenging effects obtained from each mushroom methanolic extract.

Overall, L. deliciosus revealed better antioxidant properties than $T$. portentosum (lower $\mathrm{EC}_{50}$ values), which is in agreement with the higher content of phenols found in the first species. This was much more evident in $\mathrm{EC}_{50}$ values for DPPH scavenging effect $(8.52 \mathrm{mg} / \mathrm{ml}$ for $L$. deliciosus versus $22.9 \mathrm{mg} / \mathrm{ml}$ for $T$. portentosum). The use of the entire mushroom is recommended and the mushroom cap proved to be better than the stipe; particularly for $T$. portentosum the DPPH scavenging effects decreased drastically when the stipe was used. The $\mathrm{EC}_{50}$ values obtained for reducing power were better than for RSA. Searching wild sources may bring new natural products into the food industry with safer and better antioxidants that provide good protection against the oxidative damage, which occurs both in the body and our daily foods. Therefore, new wild edible mushrooms, as natural sources, could be introduced for this purpose. As far as our literature survey could ascertain, little information was available on the in vitro antioxidative activities of European wild mushrooms and it is the first time that Portuguese wild edible mushrooms were submitted to these studies.

\section{Acknowledgement}

The authors are grateful to Foundation for Science and Technology (POCI/AGR/56661/2004) for financial support of this work.

\section{References}

Amarowicz, R., Pegg, R. B., Rahimi-Moghaddam, P., Barl, B., \& Weil, J. A. (2004). Free-radical scavenging capacity and antioxidant activity of selected plant species from the Canadian prairies. Food Chemistry, 84, 551-562.

Baptista, P., Branco, S., Martins, A. (2003). Preliminary evaluation of edible mushroom biodiversity and production in the Northeast of
Portugal. In Proceedings of the third international workshop on edible mycorrhizal mushrooms: ecology, physiology and cultivation, Canada, Victoria.

Bon, M. (1988). In Guia de campo de los Hongos de Europa. Barcelona: Ediciones Omega.

Cheung, L. M., Cheung, P. C. K., \& Ooi, V. E. C. (2003). Antioxidant activity and total phenolics of edible mushroom extracts. Food Chemistry, 81, 249-255.

Courtecuisse, R. (1999). In Mushrooms of Britain and Europe. London: HarperCollins Publishers.

Courtecuisse, R., \& Duhem, B. (1995). In Mushrooms and Toadstools of Britain and Europe. London: HarperCollins Publishers.

Halliwell, B. (1997). Antioxidants in human health and disease. Annual Review of Nutrition, 16, 33-50.

Halliwell, B., \& Gutteridge, J. M. C. (1999). Free radicals in biology and medicine (3rd ed.). Oxford: Oxford University Press.

Hatano, T., Kagawa, H., Yasuhara, T., \& Okuda, T. (1988). Two new flavonoids and other constituents in licorice root: their relative astringency and radical scavenging effects. Chemical and Pharmaceutical Bulletin, 36, 2090-2097.

Marchand, A. (1971-1986). In Champignons du Nord et du Midi (Tome 19). Soc. Mycol. Pyrénées Mediterranéenes, Perpignan.

Martins, A., Baptista, P., Sousa, M. J., Meireles, T., Pais, M. S. (2002). Edible mycorrhizal fungi associated with Castanea sativa Mill trees in the Northeast of Portugal. In I. Hall, Wang Yun, E. Danell, A. Zambonelli (Eds.). Proceedings of the second international workshop on edible mycorrhizal fungi. ISBN 0-478-10828-X.

Mau, J. L., Chang, C.-N., Huang, S.-J., \& Chen, C.-C. (2004). Antioxidant properties of methanolic extracts from Grifola frondosa, Morchella esculenta and Termitomyces albuminosus mycelia. Food Chemistry, 87, 111-118.

Mau, J.-L., Lin, H.-C., \& Song, S.-F. (2002). Antioxidant properties of several speciality mushrooms. Food Research International, 35, 519-526.

Moser, M. (1983). In Keys to Agarics and Boleti (Polyporales, Boletales, Agaricales, Russulales). London: Roger Phillips.

Nakayama, T., Yamada, M., Osawa, T., \& Kawakishi, S. (1993). Suppression of active oxygen-induced cytotoxicity by flavonoids. Biochemical Pharmacology, 45, 265-267.

Ostrovidov, G., Franck, P., Joseph, D., Martarello, L., Kirsch, G., Belleville, F., Nabet, P., \& Dousset, B. (2000). Screening of new antioxidant molecules using flow cytometry. Journal of Medicinal Chemistry, 43, 1762-1769.

Oyaizu, M. (1986). Studies on products of browning reactions: antioxidative activities of products of browning reaction prepared from glucosamine. Japanese Journal of Nutrition, 44, 307-315.

Sagakami, H., Aohi, T., Simpson, A., \& Tanuma, S. (1991). Induction of immunopotentiation activity by a protein-bound polysaccharide, PSK. Anticancer Research, 11, 993-1000.

Shimada, K., Fujikawa, K., Yahara, K., \& Nakamura, T. (1992). Antioxidative properties of xanthan on the autoxidation of soybean oil in cyclodextrin emulsion. Journal of Agriculture and Food Chemistry, 40, 945-948.

Singleton, V. L., \& Rossi, J. A. Jr., (1965). Colorimetric of total phenolics with phosphomolybdic-phosphotungstic acid reagents. American Journal of Enology and Viticulture, 16, 144-158.

Valentão, P., Andrade, P. B., Rangel, J., Ribeiro, B., Silva, B. M., Baptista, P., \& Seabra, R. M. (2005a). Effect of the conservation procedure on the contents of phenolic compounds and organic acids in Chanterelle (Cantharellus cibarius) mushroom. Journal of Agricultural and Food Chemistry, 53, 4925-4931.

Valentão, P., Lopes, G., Valente, M., Barbosa, P., Andrade, P. B., Silva, B. M., Baptista, P., \& Seabra, R. M. (2005b). Quantitation of nine organic acids in wild mushrooms. Journal of Agricultural and Food Chemistry, 53, 3626-3630.

Velioglu, Y. S., Mazza, G., Gao, L., \& Oomah, B. D. (1998). Antioxidant activity and total phenolics in selected fruits, vegetables, and grain products. Journal of Agriculture and Food Chemistry, 46, 4113-4117. 
Wasser, S. P., \& Weis, A. L. (1999). Medicinal properties of substances occurring in higher Basidiomycetes mushrooms: current perspective (review). International Journal of Medicinal Mushrooms, $1,31-62$.
Yen, G.-C., \& Hung, C.-Y. (2000). Effects of alkaline and heat treatment on antioxidative activity and total phenolics of extracts from Hsiantsao (Mesona procumbens Hemsl.). Food Research International, 33, $487-492$. 